\title{
Transformation Sequence Rule of Martensite Plates and Temperature Memory Effect in Shape Memory Alloys
}

\author{
Tian-Wei Liu ${ }^{1}$ Yan-Jun Zheng ${ }^{1} \cdot$ Li-Shan Cui $^{1}$
}

Received: 19 July 2015/Revised: 30 August 2015/Published online: 12 October 2015

(C) The Chinese Society for Metals and Springer-Verlag Berlin Heidelberg 2015

\begin{abstract}
In thermoelastic martensitic transformation, it is well established that the first martensite plate appearing upon cooling becomes the final one during reverse transformation to austenite upon heating. The results obtained from this work show that the transformation sequence of the martensite appears to be random. Newly formed martensite plates can modify the elastic strain energy level stored in the already existing martensite. Additionally, the elastic strain energy stored in newly formed martensite is not necessarily to be higher than the remaining martensite. The obtained results may assist in understanding phenomena related to partial transformation of shape memory alloys, such as temperature memory effect.
\end{abstract}

\section{KEY WORDS: Phase transformation; Shape memory alloys; TEM; Transformation sequence}

\section{Introduction}

Shape memory alloys (SMAs) are expected to be used widely as actuators in smart systems; however, their applications are still limited. One of the major reasons for their limited application is that the response of SMAs on external stimulation is nonlinear and thermal history dependent $[1,2]$. These cause difficult in controlling them accurately. The complex thermo-mechanical behaviors of SMAs originated from the complexity of the thermoelastic martensitic transformation [3-5], which contents irreversible components $[6,7]$ and is directly influenced by external stress [8,9] and temperature [10,11]. Thus, a deep understanding of thermoelastic martensitic transformation is very important to widen the application of SMAs.

Available online at http://link.springer.com/journal/40195

Yan-Jun Zheng

zhengyj@cup.edu.cn

1 Department of Materials Science and Engineering, China University of Petroleum, Beijing 102249, China
Thermoelastic phase transformation is known to be controlled by a local balance between the chemical and non-chemical forces [7]. The chemical forces arise from the Gibbs free energy differences between the parent phase and martensite. However, the non-chemical forces are composed of two parts: (1) elastic strain energy that depends on the changes occurred in shape and volume of the product during transformation and (2) dissipation energy that is the internal work dissipated during phase transformation [7]. Thus, it is difficult to measure the elastic strain energy level. But it is well accepted that the minimum level of the elastic strain energy should be stored in the first martensite plate [7]. It gradually builds up in the martensite plates that form later, and final martensite plate contains maximum level as usual. The elastic strain energy serves as driving force during the reverse phase transformation. Consequently, the appearance and disappearance of the martensite plates follow a sequential order: the plate appearing first on cooling will transform back to original at the last on heating [7, 12].

In this work, by using an optical microscope with an improved depth of field, we find that the transformation sequence is actually random. By using transmission electron microscope (TEM), we find that the newly formed 
martensite can modify the twin structure of those already existing martensite plates. Furthermore, by using differential scanning calorimetry (DSC), we find that the elastic strain energy stored in the newly formed martensite is not necessarily higher than that in the already existing martensite plates. These findings may help to understand phenomena related to the partial transformation of the SMAs, for example the so-called temperature memory effect (TME) [13].

\section{Experimental}

NiTi alloy of single crystal and polycrystalline rods were obtained from the Generous Research Institute for Nonferrous Metals, China. The composition of the alloy is Ti$51 \mathrm{Ni}$ (in at\%). Rods were spark cut into bars of $100 \mathrm{~mm} \times 10 \mathrm{~mm} \times 2 \mathrm{~mm}$ in dimension. The bars were vacuum annealed at $1123 \mathrm{~K}$ for $1 \mathrm{~h}$ and then quenched into ice water.

In order to stabilize the transformation temperatures, the bars were globally cycled three times from below $M_{\mathrm{f}}$ (martensitic finishing temperature) to above $A_{\mathrm{f}}$ (austenitic finishing temperature). DSC specimens were incompletely thermally cycled between $T_{\mathrm{m}}$ (peak temperature of cooling) and $T_{\mathrm{a}}$ (peak temperature of heating). DSC testing was conducted using a Netzsch DSC 2004 Phoenix with a heating and cooling rate of $5 \mathrm{~K} / \mathrm{min}$.

The specimens for optical observation were electropolished using the electrolyte consisted of $25 \% \mathrm{HNO}_{3}$ and $75 \% \mathrm{CH}_{3} \mathrm{OH}$. Thereafter, optical observation was carried out using a Leica DM2500 P equipped with a heating/cooling stage of $0.1 \mathrm{~K}$ control accuracy. An objective lens aperture was placed into the optical path and was adjusted to its smallest diameter for an increased depth of field.

The samples for transmission electron microscopy (TEM) were ground to a thickness of about $50 \mu \mathrm{m}$ and then subjected to twin-jet electro-polishing. The electrolyte is consisted of $25 \% \mathrm{HNO}_{3}$ and $75 \% \mathrm{CH}_{3} \mathrm{OH}$. TEM observation was carried out using JEM-2100 operating at $200 \mathrm{kV}$ with a heating/cooling stage of $0.01 \mathrm{~K}$ control accuracy. The specimen was thermally cycled in situ from 103.00 (below $M_{\mathrm{f}}$ ) to $262.00 \mathrm{~K}$, which is in between $A_{\mathrm{s}}$ (austenitic starting temperature) and $A_{\mathrm{f}}$.

\section{Results and Discussion}

Figure 1 shows the optical observation of surface relief in the $\mathrm{Ti}-51 \mathrm{Ni}$ (at\%) polycrystalline sample during cooling. The sample surface was smooth and flat prior to the first martensite plate formation. The first martensite plate which is marked as A appeared in the view at decreased temperature. With further decreasing the temperature, the martensite plates marked as $\mathrm{B}$ and $\mathrm{C}$ appeared successively. During reverse transformation, the plate $\mathrm{C}$ should disappear first, followed by plates B and A based on the traditional mechanism understanding. Interestingly, it was found that the plate B disappeared first followed by plates $\mathrm{A}$ and $\mathrm{C}$ (Fig. 2).

It must be noted that the results shown in Figs. 1 and 2 were not a single case. Repeated observations indicated that the appearance and disappearance of the martensite plates follow a relatively random sequence. This is very interesting because the widely accepted rule that "the plate appearing first on cooling will transform back to original state at the last during heating" [7, 12] is indeed reasonable. The first martensite plate is surrounded by parent phase, and its elastic strain can be relatively easily relaxed. Succeeding martensite plates have to nucleate or grow in an already elastically distorted parent phase, and therefore, the level of strain energy builds up. As the strain energy serves as driving force during the reverse transformation, thus the martensite plates appeared earlier with a lower level of the elastic strain energy should disappear later. The contradictory results in Figs. 1 and 2 suggest two possibilities, either newly formed martensite plates are capable of modifying the strain energy level of existing martensite plates or newly formed martensite does not necessarily store a higher level of elastic strain energy.

In order to verify the phenomenon further, TEM observation was performed. Figure $3 \mathrm{a}$, b shows the brightfield images after the first and third partial cycling. Interfaces of austenite-martensite are highlighted using a chaindashed curve and dot-dashed curve. It is obvious that the curves separate into two distinct regions (Fig. 3a-b). One of the regions undergoes a martensitic transformation during partial transformation, and the other remains all the way as martensite state (martensite zone). Whether the partial transformation modified the martensite zone or not? Figure $3 \mathrm{c}, \mathrm{d}$ shows the martensite zone at higher magnifications of Fig. 3a, b, respectively. Figure 3c displays some twin boundaries, marked as 1, 2 and 3 after the first heating. However, these twin boundaries disappeared after the third heating (Fig. 3d). The results indicate that the formation of new martensite can modify the structure of the already existing martensite.

Whether the newly formed martensite can always store a higher level of the elastic strain energy than the existing martensite plates or not? In tradition, it is accepted that during a forward transformation, the martensite plates with a higher strain energy level will form at the temperatures lower than those with a lower strain energy level. Figure 4a shows a speculation curve based on the traditional understanding $[7,12]$. If the heating is stopped at the temperature 

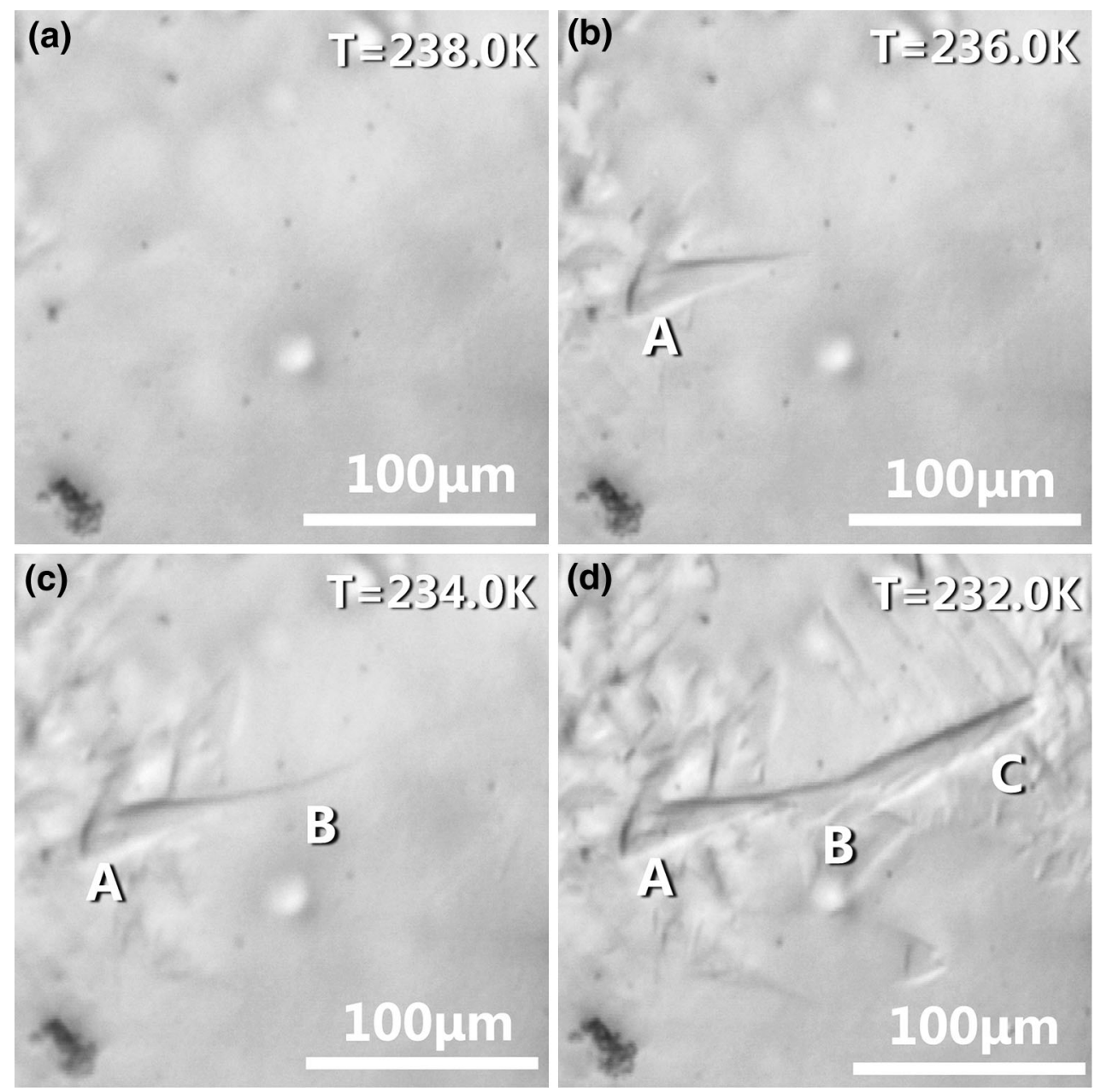

Fig. 1 Surface relief of NiTi polycrystalline specimen during cooling. a At $238.0 \mathrm{~K}$, in full austenite state, b the plate A appeared at $236.0 \mathrm{~K}$, c the plate B appeared at $234.0 \mathrm{~K}$, d the plate C appeared at $232.0 \mathrm{~K}$

where the endothermic peak just reaches its top, there should be some martensite left. The gray area in Fig. 4a corresponds to the remaining martensite volume. If both the temperature is decreased from endothermic peak temperature and the newly formed martensite stores a higher level of the elastic strain energy than the remaining martensite volume, then the forward transformation should commence at the lower temperature side to the gray area on the cooling curve. However, the experimental results shown in Fig. 4b indicate that the newly formed martensite formed at around the $M_{\mathrm{S}}$ (martensitic starting temperature). It means that it encountered less energy barrier than the expected. In other words, it stored less elastic strain energy than some already existing martensite. It should be noted that the results in Fig. 4 do not suggest that in a successive forward transformation. It just confirms that in a partial transformation cycle when the reverse transformation is interrupted and the temperature starts to decrease.
Experimental results in this study may help in understanding phenomena related to partial transformation of SMAs, for example TME [13]. It has been learned that an incomplete transformation cycle of the SMAs may induce a kinetic stop in the next reverse transformation process. This phenomenon has many different explanations [10, 11, 13]. Elastic strain energy and dislocations are thought to be the main reason. Transformation characteristic such as transformation temperature could be changed during thermal cycling [14, 15], and defects could be introduced in this process. Therefore, the dislocations which accumulated at the martensite-parent phase interface are cited as one explanation [16, 17]. On the other hand, elastic strain energy serves as driving force in the reverse transformation, and the modification of the elastic strain energy stored in martensite plates is thought to be another reasonable explanation [18]. Results in this work confirmed the structural modification of the existing martensite, and 

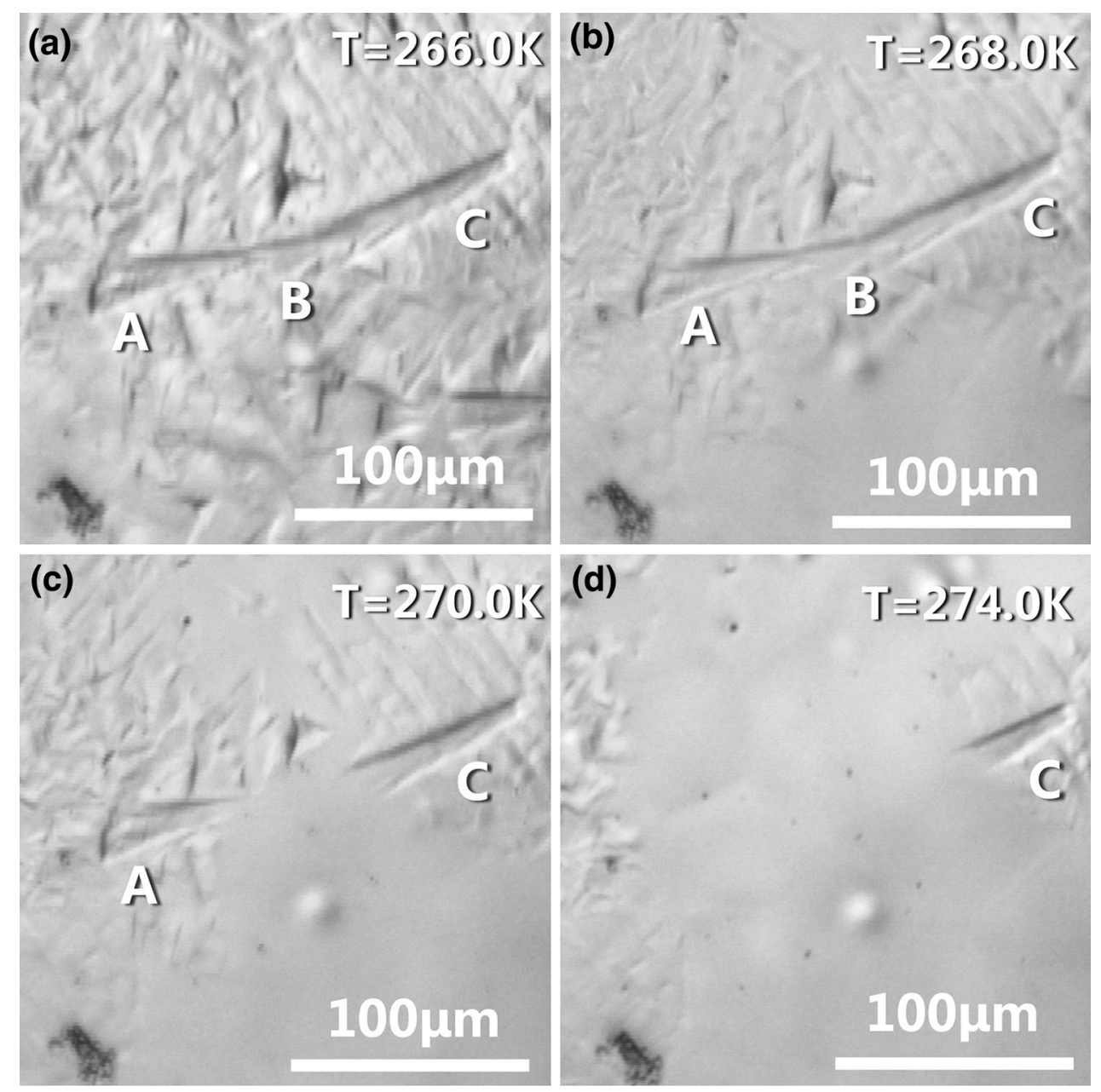

Fig. 2 Surface relief of NiTi polycrystalline specimen during heating. a At $266.0 \mathrm{~K}$, b at $268.0 \mathrm{~K}$, where the martensite plates started to disappear, $\mathbf{c}$ the plate B disappeared at $270.0 \mathrm{~K}$, $\mathbf{d}$ the plate A disappeared at $274.0 \mathrm{~K}$, leaving plate $\mathrm{C}$ alone

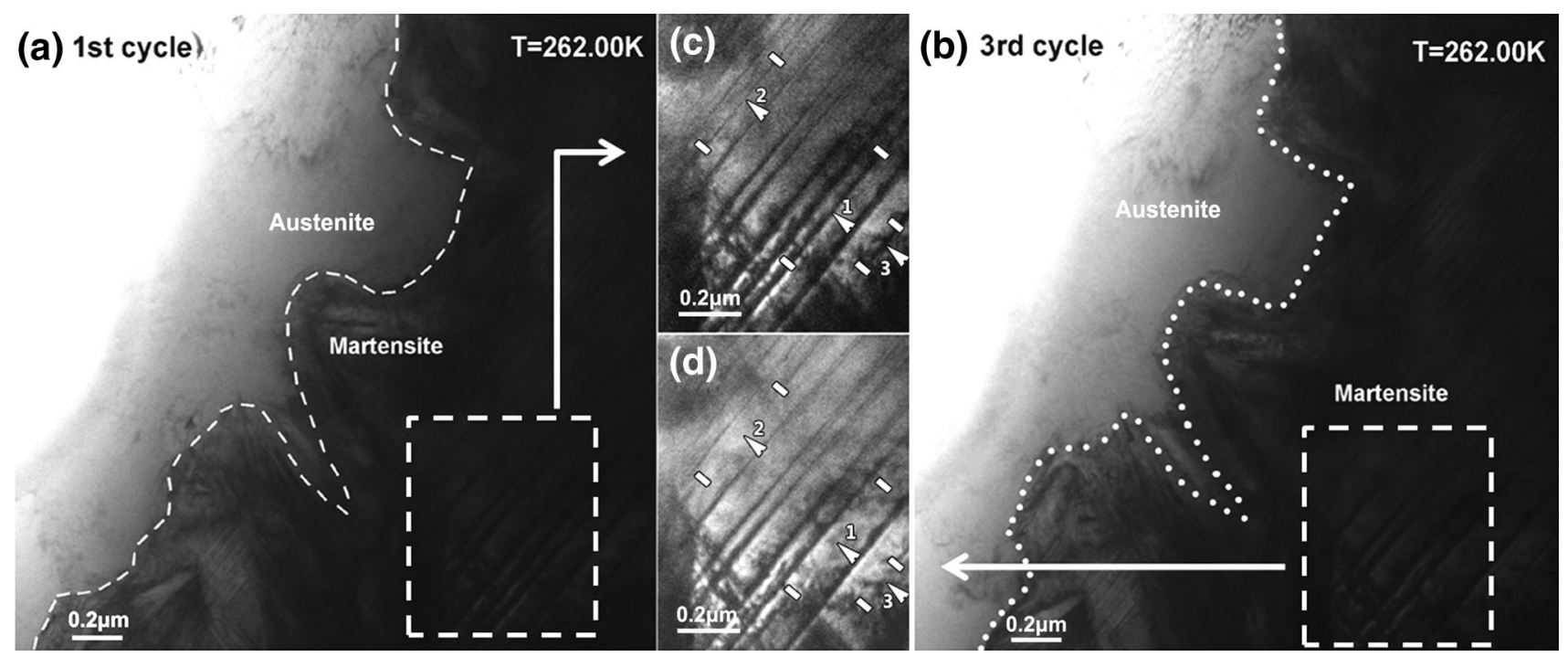

Fig. 3 Bright-field TEM images of the single-crystal NiTi alloy. The sample was incompletely cycled from $103.00 \mathrm{~K}$ (below $M_{\mathrm{f}}$ ) to $262.00 \mathrm{~K}$ (in between $A_{\mathrm{s}}$ and $A_{\mathrm{f}}$ ). a At $262.00 \mathrm{~K}$ after the first incomplete transformation cycle, $\mathbf{b}$ at $262.00 \mathrm{~K}$ after the third incomplete transformation cycle, $\mathbf{c}, \mathbf{d}$ local magnifications of $\mathbf{a}$ and $\mathbf{b}$, respectively 

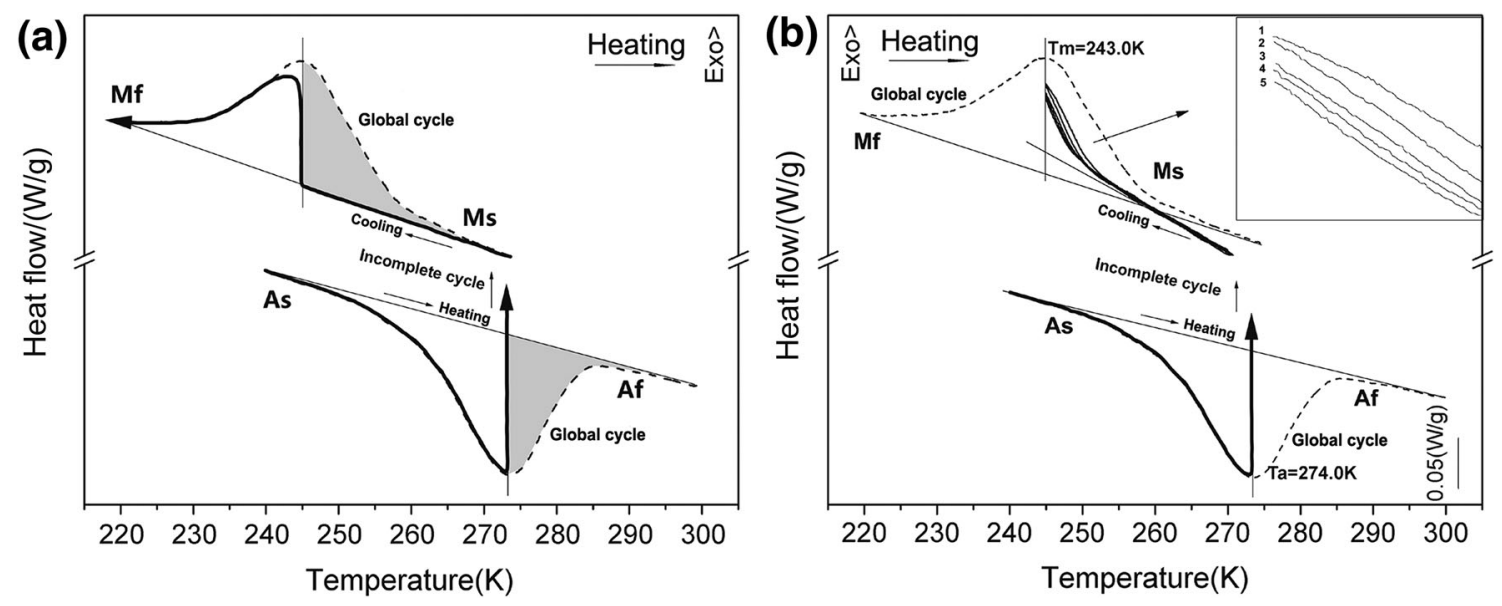

Fig. 4 DSC curves of incomplete martensitic transformation, wherein global curves of complete martensitic transformation are also shown for comparison. a A speculation DSC curve based on the traditional understanding of the elastic strain energy, b DSC curves of incomplete transformation

therefore, the elastic strain energy level is at least one contribution to TME. Rodriguez-Aseguinolaza et al. [18] recently proposed that if the reverse transformation is stopped and then the temperature decreases, the newly formed martensite starts to build elastic strain energy up from zero. Therefore, in the next complete transformation cycle, two groups of the martensite with different elastic strain energy levels will leave a gap in between themselves. In contrast, based on the results of this paper, it can be said that the newly formed martensite does not build the elastic strain energy up from zero, but from a relatively low level, at least lower than those stored in some already existing martensite.

\section{Conclusions}

In summary, this paper gives a direct observation of transformation sequence of the martensite plates. It is found that the martensite plates appear and disappear relatively randomly. TEM observation confirmed that newly formed martensite may modify the structure and the elastic strain energy level of existing martensite. DSC results suggest that in a partial transformation, the newly formed martensite plate stores the elastic strain energy lower than some martensite plates already existing in the system.
Acknowledgments This research was supported by Science Foundation of China University of Petroleum, Beijing (No. KYJJ2012-0625).

\section{References}

[1] G. Airoldi, A. Corsi, G. Riva, Scr. Mater. 36, 1273 (1997)

[2] G. Airoldi, A. Corsi, G. Riva, Mater. Sci. Eng., A 241, 233 (1998)

[3] M.W.M. van der Wijst, Dissertation, TU Eindhoven, 1992

[4] K. Otsuka, X. Ren, Prog. Mater Sci. 50, 511 (2005)

[5] D.R. Ni, Z.Y. Ma, Acta Metall. Sin. (Engl. Lett.) 27, 739 (2014)

[6] P. Wollants, J.R. Roos, L. Delaey, Prog. Mater Sci. 37, 227 (1993)

[7] J. Ortinh, A. Planes, Acta Metall. 36, 1873 (1988)

[8] H.C. Tong, C.M. Wayman, Scr. Metall. 8, 93 (1974)

[9] L. Porcar, P. Courtois, G. Crouigneau, J. Debray, D. Bourgault, Appl. Phys. Lett. 105, 151907 (2014)

[10] G. Airoldi, G. Riva, Key Eng. Mater. 48, 5 (1990)

[11] K. Madangopal, S. Banerjee, S. Lele, Acta Metall. Mater. 42, 1875 (1994)

[12] D.P. Dunne, C.M. Wayman, Metall. Trans. 4, 137 (1973)

[13] Y.J. Zheng, L.S. Cui, J. Schrooten, Appl. Phys. Lett. 84, 31 (2004)

[14] S. Miyazaki, Y. Igo, K. Otsuka, Acta Metall. 34, 2045 (1986)

[15] X.L. Lu, D.X. Su, F. Chen, W.L. Liu, Y.G. Shi, Y.X. Tong, L. Li, Acta Metall. Sin. (Engl. Lett.) 28, 243 (2015)

[16] T. Tadaki, T. Kakeshita, K. Shimizu, J. Phys. 43, 191 (1982)

[17] Y.J. Zheng, J.T. Li, L.S. Cui, Mater. Lett. 63, 949 (2009)

[18] J. Rodríguez-Aseguinolaza, I. Ruiz-Larrea, M.L. Nó, A. LópezEcharri, J. San Juan, J. Appl. Phys. 107, 083518 (2010) 